\title{
PERBANDINGAN TINGKAT STRES AKNE VULGARIS RINGAN DENGAN AKNE VULGARIS BERAT PADA MAHASISWA PENDIDIKAN DOKTER FAKULTAS KEDOKTERAN UNIVERSITAS MALAHAYATI
}

\author{
Eka Silvia1, Resati Nando Panonsih2, Ratna Purwaningrum3, Dwi Rhavena Rhavika4
}

1Departemen Fisiologi, Fakultas Kedokteran, Universitas Malahayati

2Bagian Dermatologi, Rumah Sakit Pertamina Bintang Amin

3Departemen Histologi, Fakultas Kedokteran, Universitas Malahayati

4Program Studi Kedokteran, Fakultas Kedokteran, Universitas Malahayati

\begin{abstract}
Comparison of Stress Level Mild Acne Vulgaris with Heavy Acne Vulgaris in Medical Education Students, Faculty of Medicine, University of Malahayati. Acne vulgaris is the most common disease globally in adolescents who are puberty and young adults with varying severity, at least every individual who has puberty once suffered from acne vulgaris. The most common predilection of acne vulgaris is the face and neck, back and chest. the cause of acne vulgaris is very multifactorial one of which is psychological stress, stress can increase the production of androgen hormones, these hormones will increase the production of sebum, thus facilitating the process of forming blackheads in the predilection area. Knowing the comparison between stress levels of mild acne vulgaris with stress levels of severe acne vulgaris based on the Lehmann classification at medical students 2015-2018 faculty of Malahayati Univesity on 2019. Using a cross-sectional, quantitative, comparative approach with observational analytic design. The source of research data used primary data obtained from Malahayati University Medical School students who met the inclusion criteria as 76 students consisting of 38 students who has mild acne vulgaris and 38 students who has severe acne vulgaris. Stress levels were examined using the Kessler questionnaire. Obtained from 76 respondens according to the samples, 38 mild acne vulgaris samples $61 \%$ has normal stress, $34 \%$ mild stress levels and $5 \%$ moderate stress levels. In students with severe acne vulgaris with a total sample of 38 it was found that $55 \%$ has severe stress, $24 \%$ mild stress level, $16 \%$ normal stress level and $5 \%$ moderate stress level. The bivariate test results obtained $p$ value $=0,000(p$ $<0.05$ ). Conclusion there is a significant comparison between stress levels in mild acne vulgaris with severe acne vulgaris.
\end{abstract}

Keywords: Stress Levels, Mild Acne Vulgaris, Severe Acne Vulgaris

\begin{abstract}
Abstrak: Perbandingan Tingkat Stres Akne Vulgaris Ringan dengan Akne Vulgaris Berat Pada Mahasiswa Pendidikan Dokter Fakultas Kedokteran Universitas Malahayati. Akne vulgaris merupakan penyakit terbanyak yang dialami oleh remaja yang sedang pubertas dan dewasa muda dengan tingkat keparahan yang bervariasi, sedikitnya setiap individu yang sudah pubertas pernah sekali menderita akne vulgaris. Predileksi tersering pada akne vulgaris adalah wajah dan leher, punggung dan dada. penyebab akne vulgaris sangat multifaktorial salah satunya adalah stres, stres dapat meningkatkan produksi hormon androgen, hormon tersebut akan meningkatkan produksi sebum, sehingga memudahkan proses terbentuknya komedo didaerah predileksi. Tujuan penelitian in untuk mengetahui perbandingan tingkat stres akne vulgaris ringan dengan akne vulgaris berat berdasarkan klasifikasi Lehmann pada mahasiswa angkatan 2015-2018 prodi pendidikan dokter Fakultas Kedokteran Universitas Malahayati. Menggunakan pendekatan crosssectional, kuantitatif, komparatif dengan desain analitik observasional. Sumber data penelitian menggunakan data primer yang diperoleh dari mahasiswa Fakultas Kedokteran Universitas Malahayati yang memenuhi kriteria inklusi sebanyak 76 mahasiswa yang terdiri dari 38 mahasiswa yang mengalami akne vulgaris ringan dan 38 mahasiswa yang mengalami akne vulgaris berat. Tingkat stres diperiksa menggunakan kuesioner Kessler. Dari 38 sampel akne vulgaris ringan sebanyak $61 \%$ mengalami stres normal, $34 \%$ tingkat stres ringan dan 5\% tingkat stres sedang. Pada mahasiswa dengan akne vulgaris berat dengan total sampel 38 didapatkan hasil 55\% mengalami stres berat, $24 \%$ tingkat stres ringan, $16 \%$ tingkat stres normal dan $5 \%$ tingkat stres sedang. Hasil uji bivariat diperoleh $p$
\end{abstract}


value $=0,000(p<0,05)$. Kesimpulanya terdapat perbandingan yang signifikan antara tingkat stres pada akne vulgaris ringan dengan akne vulgaris berat.

Kata Kunci:Akne Vulgaris Ringan, Akne Vulgaris Berat, Tingkat Stres

\section{PENDAHULUAN}

Akne vulgaris merupakan penyakit terbanyak yang dialami oleh remaja usia 15-18 tahun, akne vulgaris biasanya dimulai pada usia 12-15 tahun, dengan puncak tingkat keparahan pada usia 1721 tahun. (Sitohang dan Wasitatmadja, 2016).

Prevalensi di negara-negara maju seperti Amerika Serikat, Asia Pasifik, Kanada dan Eropa Barat berbeda dengan negara berkembang maupun negara SubSahara Afrika, Oceania, Amerika Latin dan Karibia. Hal ini disebabkan oleh perbedaan etnis yang diteliti tidak sama satu sama lain pada wilayah-wilayah tersebut. Dimana didapatkan hasil 10 dari 425 remaja dalam rentang usia 10 sampai 17 tahun (rata-rata usia 13,3 tahun) sebanyak 56,5\%-65,7\% menujukan akne vulgaris ringan sebagai bentuk yang paling umum dari akne vulgaris, diikuti oleh bentuk akne vulgaris sedang sebanyak 26,3\%-34,9\%, kemudian bentuk akne vulgaris berat sebanyak 5,1\%-10,1\%. Sementara itu dibeberapa negara seperti Taiwan (Asia Timur), Eropa Barat dan Asia Selatan memiliki prevalensi tertinggi dalam kelompok usia 15-19 tahun.Prevelansi Akne vulgaris tertinggi yaitu pada usia 14-17 tahun, yang dialami oleh sekitar $83-85 \%$ wanita di Indonesia dan pria yang menderita akne vulgaris pada usia 16-19 tahun sekitar 95-100\%. Lesi Akne vulgaris yang predominan yang dialami adalah komedo dan papul serta jarang terlihat lesi beradang. Akne vulgaris dapat terjadi pertama kali saat premenarke maupun setelah usia 25 tahun pada wanita, setelah masa remaja kelainan ini berangsur berkurang. Akne vulgaris dapat menetap sampai dekade 30-an atau bahkan lebih, meskipun pada pria umumnya akne vulgaris lebih cepat berkurang namun dari hasil beberapa penelitian membuktikan bahwa akne vulgaris pada pria gejalanya lebih berat (Hidayati, 2017). Pertumbuhan akne vulgaris disebabkan oleh berbagai faktor seperti genetik, endokrin (androgen, pituitary sebotropic), keaktifan dari kelenjar sebasea, faktor psikis, musim, faktor stres, infeksi bakteri (Propionibacterium acnes), kosmetika, dan bahan kimia yang lain. Gangguan ini dianggap hal yang biasa semata-mata dihubungkan dengan pubertas namun bukti ilmiah telah menggambarkan bahwa efek dari kondisi ini jauh lebih dari apa yang dilihat di luar kulit saja. (Latifah dan Kurniawaty, 2015)

Menurut catatan studi dermatologi kosmetika Indonesia menunjukan $60 \%$ dari total populasi yang diteliti menderita akne vulgaris yaitu pada tahun 2006, lalu meningkat menjadi $80 \%$ pada tahun 2007 dan terus meningkat sampai $90 \%$ pada tahun 2009 (Afriyanti, 2015). Dari hasil pre-survey yang dilakukan oleh peneliti pada mahasiswa pendidikan dokter difakultas kedokteran Universitas Maalahayati terdapat 521 mahasiswa dari berbaagai angkatan (2015-2018) yang sedang menderita akne vulgaris dengan berbagai grading dari ringan, sedang, berat sampai bekas akne.

Stres merupakan suatu kondisi yang dapat mempengaruhi emosi, proses berpikir dan kondisi seseorang serta menyatakan dirinya dalam bentuk penolakan, ketegangan, atau frustrasi, mengacaukan keseimbangan fisiologis dan psikologis bagi siapa saja yang sedang mengalaminya. Secara fisiologis kondisi stres akan mengakibatkan teraktivasinya HPA (Hipotalamus Pituitary Axis). Hal tersebut tentunya dapat meningkatan konsentrasi ACTH (adrenocorticotropic hormone) dan glukokortikoid yang berkepanjangan. Peningkatan ACTH akan memicu peningkatan hormon androgen yang berperan dalam merangsang peningkatan produksi sebum dan merangsang keratinosit. Peningkatan sebum dan hiperkeratinosit akan mengakibatkan timbulnya akne vulgaris. (Guyton, 2016).

Penelitian terdahulu menyatakan sebanyak $35 \%$ mahasiswa Fakultas Kedokteran Universitas Sumatera Utara angkatan 2009 memiliki tingkat stres yang ringan, kemudian $60 \%$ mahasiswa Fakultas Kedokteran Universitas Sumatera 
Utara angkatan 2009 memiliki tingkat keparahan akne vulgaris yang ringan, dan $72 \%$ mahasiswa Fakultas Kedokteran Universitas Sumatera Utara angkatan 2009 mengalami stres menderita akne vulgaris (Gautama, 2013). Dalam penelitian yang dilakukan oleh Zari dan Alrahmani (2017) didapatkan peningkatan keparahan stres sangat berkorelasi dengan peningkatan keparahan akne yang signifikan.

\section{METODE}

Penelitian ini menggunakan rancangan survey cross sectional, dimana data yang menyangkut variabel bebas atau risiko dan variabel terikat atau variabel akibat, akan dikumpulkan dalam waktu yang bersamaan. Cross sectional dipilih karena observasi atau pengumpulan data dilakukan sekaligus pada satu waktu (point time approach). Artinya, tiap subjek penelitian hanya diobservasi satu kali dan pengukuran dilakukan terhadap status karakter atau variabel subjek pada saat pemeriksaan. Hal ini tidak berarti bahwa semua subjek penelitian diamati pada waktu yang sama , melainkan setiap subjek hanya diobservasi sekali saja pada saat responden mengisi kuesioner (Notoatmodjo, 2014).

Batasan populasi yang dapat menjadi sampel dalam penelitian ini mengikuti kriteria inklusi dan ekslusi yang telah ditentukan oleh peneliti.

Pengambilan sampel menggunakan teknik total sampling dengan mempertimbangkan syarat penelitian perbandingan yaitu $\mathrm{n}_{1}=\mathrm{n}_{2}$. Jumlah keseluruhan responden dalam penelitian ini ada 76 mahasiswa Prodi Pendidikan Dokter Fakultas Kedokteran Universitas
Malahayati angkatan 2015-2018 yang sedang mengalami akne vulgaris. Pada penelitian ini karena $\mathrm{n}_{1}$ harus sama dengan n2 maka jumlah sampel akne vulgaris ringan harus setengah dari jumlah keseluruhan sampel pada penelitian ini yaitu 38 mahasiswa Prodi Pendidikan Dokter Fakultas Kedokteran Universitas Malahayati angkatan 20152018 dan jumlah sampel akne vulgaris berat harus sama dengan jumlah sampel akne vulgaris ringan yaitu 38 mahasiswa Prodi Pendidikan Dokter Fakultas Kedokteran Universitas Malahayati angkatan 2015-2018.

Variabel independen dalam penelitian ini adalah tingkat stres psikologis yang diukur menggunakan kuesioner Kessler Psychological Distress Scale (K10) dengan indeks reabilitas 0,881 dan nilai validitasnya diatas 0.2 , kuesioner ini dikembangkan oleh Kessler dan Mroczeck. Sementara itu variabel dependen dalam penelitian ini adalah insiden kejadian akne vulgaris tipe ringan dan berat, yang diukur berdasarkan hasil anamnesa dan pemeriksaan fisik dengan alat bantu lup/kaca pembesar dan penlight.

Setelah didapatkan data lalu dilakukan analisis data menggunakan uji statistik yang pertama dilakukan Uji Normalitas karena data dalam penelitian ini terdistribusi normal kemudian dilakukan Independent T-Test kedua uji tersebut menggunakan SPSS 16.

\section{HASIL DAN PEMBAHASAN}

Penelitian ini dilakukan pada 76 sampel yang memenuhi kriteria inklusi dan eksklusi.

Tabel 1. Karakteristik Responden Berdasarkan Jenis Kelamin

\begin{tabular}{cccccc}
\hline Jenis & \multicolumn{2}{c}{ AV Ringan } & \multicolumn{2}{c}{ AV Berat } & \multirow{2}{*}{ Total } \\
\cline { 2 - 5 } Kelamin & Frekuensi & Presentase & Frekuensi & Presentase & \\
\hline Laki-laki & 12 & $32 \%$ & 13 & $34 \%$ & 25 \\
Perempuan & 26 & $68 \%$ & 25 & $66 \%$ & 51 \\
\hline Total & $\mathbf{3 8}$ & $\mathbf{1 0 0} \%$ & $\mathbf{3 8}$ & $\mathbf{1 0 0} \%$ & $\mathbf{7 6}$ \\
\hline
\end{tabular}

Berdasarkan tabel diatas mayoritas yang mengalami akne vulgaris ringan dan berat adalah peremuan sebanyak 26
$(68 \%)$, orang mengalami akne vulgaris ringan dan $25(66 \%)$. orang mengalami akne vulgaris berat. 
Tabel 2. Karakteristik Responden Berdasarkan Usia

\begin{tabular}{cccccc}
\hline \multirow{2}{*}{ Usia } & \multicolumn{2}{c}{ AV Ringan } & \multicolumn{2}{c}{ AV Berat } & \multirow{2}{*}{ Total } \\
\cline { 2 - 5 } & Frekuensi & Presentase & Frekuensi & Presentase & \\
\hline 18 tahun & 5 & $13 \%$ & 6 & $16 \%$ & 11 \\
19 tahun & 14 & $37 \%$ & 10 & $26 \%$ & 24 \\
20 tahun & 9 & $24 \%$ & 15 & $39 \%$ & 24 \\
21 tahun & 6 & $16 \%$ & 6 & $16 \%$ & 12 \\
22 tahun & 2 & $5 \%$ & 1 & $3 \%$ & 3 \\
23 tahun & 1 & $2,5 \%$ & 0 & $0 \%$ & 1 \\
24 tahun & 1 & $2,5 \%$ & 0 & $0 \%$ & 1 \\
\hline Total & $\mathbf{3 8}$ & $\mathbf{1 0 0} \%$ & $\mathbf{3 8}$ & $\mathbf{1 0 0} \%$ & $\mathbf{7 6}$ \\
\hline
\end{tabular}

Berdasarkan tabel 2 distribusi frekuensi usia diatas mayoritas responden penelitian mengalami akne vulgaris ringan berusia 19 tahun sebanyak 14 orang
(37\%), dan mayoritas responden penelitian mengalami akne vulgaris berat berusia 20 tahun sebanyak 15 orang (39\%).

Tabel 3. Karakteristik responden berdasarkan tingkat keparahan akne vulgaris

\begin{tabular}{ccc}
\hline Tingkat AV & Frekuensi & Presentase \\
\hline Ringan & 38 & $50 \%$ \\
Berat & 38 & $50 \%$ \\
\hline Total & $\mathbf{7 6}$ & $\mathbf{1 0 0 \%}$ \\
\hline
\end{tabular}

Berdasarkan tabel diatas jumlah responden penelitian ini terdiri dari 38 orang (50\%) akne vulgaris ringan dan 38 orang $(50 \%)$ akne vulgaris berat.

Tabel 4. Karakteristik responden berdasarkan tingkat stres

\begin{tabular}{cccc}
\hline \multirow{2}{*}{ Tingkat Stres } & AV Ringan & AV Berat & \multirow{2}{*}{ Total } \\
\cline { 2 - 3 } & Frekuensi & Frekuensi & \\
\hline Normal & 23 & 6 & 29 \\
Ringan & 13 & 9 & 22 \\
Sedang & 2 & 2 & 4 \\
Berat & 0 & 21 & 21 \\
\hline Total & $\mathbf{3 8}$ & $\mathbf{3 8}$ & $\mathbf{7 6}$ \\
\hline
\end{tabular}

Berdasarkan tabel diatas distribusi frekuensi karakteristik populasi berdasarkan tingkat stres pada akne vulgaris ringan yaitu responden yang mengalami stres normal sebanyak 23 orang $(61 \%)$, responden yang mengalami stres ringan sebanyak 13 orang (34\%), responden yang mengalami stres sedang sebanyak 2 orang (5\%), dan tidak terdapat responden yang mengalami stres berat. Sedangkan tingkat stres pada akne vulgaris berat yaitu responden yang mengalami stres normal sebanyak 6 orang $(16 \%)$, stres ringan sebanyak 9 orang $(24 \%)$, stres sedang sebanyak 2 orang $(5 \%)$, dan stres berat sebanyak 21 orang $(55 \%)$.

Tabel 5. Hasil Analisis Uji Normalitas

\begin{tabular}{lccc} 
& $\begin{array}{c}\text { Akne } \\
\text { Vulgaris }\end{array}$ & Kolmogorov-Smirnov & Shapiro-Wilk \\
\cline { 3 - 4 } & & Sig. & Sig. \\
\hline \multirow{2}{*}{ Skor Kessler 10 } & Ringan & $.200 *$ & .296 \\
& Berat & $.200 *$ & .446 \\
\hline
\end{tabular}

Uji normalitas. Hasil uji dengan Kolmogorov-Smirnov dan Shapiro-Wilk > 0,05 
Berdasarkan tabel diatas diatas
diketahui hasil pengujian dengan
Kolmogorov-Smirnov maupun Shapiro-

Wilk didapatkan hasil >0,05 data tersebut dikatakan terdistribusi normal.

Tabel 6. Hasil Analisis Independent T-Test

\begin{tabular}{lcc}
\hline & $\begin{array}{c}\text { Mean } \\
\text { (Rata-rata) }\end{array}$ & Nilai p \\
\hline AV Ringan $(n=38)$ & 18.47 & 0,000 \\
AV Berat $(n=38)$ & 28.66 & 0,000 \\
\hline
\end{tabular}

Uji Independent T-Test. Rerata rangking AV Ringan 18,47; AV Berat 28,66.

Berdasarkan tabel diatas diketahui hasil uji statistik dengan Independent $T$ Test. diperoleh $p$ value $=0,000(p<0,05)$ yang berarti bahwa Ho ditolak dan $\mathrm{Ha}$ dapat diterima yang artinya terdapat perbandingan yang signifikan antara tingkat stres dengan akne vulgaris.

\section{KESIMPULAN}

Berdasarkan hasil penelitian yang dilakukan pada mahasiswa prodi pendidikan dokter angkatan 2015-2018 fakultas kedokteran Universitas Malahayati sebanyak 76 responden yang menjadi subyek penelitian ini yaitu 38 mahasiswa dengan akne vulgaris ringan dan 38 mahasiswa dengan akne vulgaris berat, maka dapat diambil kesimpulan sebagai berikut:

1. Distribusi frekuensi tingkat stres akne vulgaris ringan pada mahasiswa prodi pendidikan dokter fakultas kedokteran Universitas Malahayati didapati responden yang sedang mengalami stres normal sebanyak 23 orang $(61 \%)$, stres ringan sebanyak 13 responden $(34 \%)$, stres sedang sebanyak 2 responden (5\%), dan tidak didapati mahasiswa yang mengalami stres berat pada akne vulgaris ringan.

2. Distribusi frekuensi tingkat stres akne vulgaris berat pada mahasiswa prodi pendidikan dokter fakultas kedokteran Universitas Malahayati didapati responden yang sedang mengalami stres normal sebanyak 6 orang $(16 \%)$, stres ringan sebanyak 9 orang $(24 \%)$, stres sedang sebanyak 2 orang (5\%), dan stres berat sebanyak 21 orang (55\%).

3. Tingkat stres normal dapat mempengaruhi kejadian akne vulgaris ringan, data penelitian menyebutkan bahwa akne vulgaris ringan sebanyak 23 orang $(61 \%$ dari responden akne vulgaris ringan ) mengalami stress dengan kategori normal berdasarkan hasil pengukuran menggunakan kuesioner.

4. Data penelitian menyebutkan sebanyak $55 \%$ atau 21 orang responden yang mengalami akne vulgaris berat memiliki tingkatan stres berat.

5. Hasil uji bivariat untuk mencari perbandingan menggunakan prinsip statistik alternatif yaitu Independent $T$-Test dan diperoleh $p$ value $=0,000$ $(p<0,05)$ yang artinya terdapat perbandingan yang signifikan antara tingkat stres dengan akne vulgaris. Semakin tinggi tingkatan stres yang dialami oleh seseorang maka semakin berat keparahan akne vulgaris yang dialami.

\section{DAFTAR PUSTAKA}

Afriyanti, R.N. (2015). Akne vulgaris pada remaja. Jurnal Majority, 4(6), pp.10-17.

Gautama, S. (2013). Gambaran Tingkat Stres dan Kejadian Akne Vulgaris pada Mahasiswa Fakultas Kedokteran Universitas Sumatera Utara Angkatan 2009. e-jurnal Fakultas Kedokteran USU, 1(1).

Guyton, A.C., Hall, J.E. (2016). Buku Ajar Fisiologi Kedokteran (Vol. 12). Singapore: Elsevier.

Hidayati, N.Z. and Riyanto, P., (2017). Hubungan Tingkat Stres Dengan Derajat Keparahan Akne Vulgaris (Studi Pada Mahasiswi Fakultas Kedokteran Universitas Diponegoro Angkatan 2012-2015). Jurnal Kedokteran Diponegoro, 6(2), Pp.964-974.

Latifah, S., \& Kurniawaty, E. (2015). Stres dan akne vulgaris. Majority, 129. 
Notoatmodjo, S. 2014. Metodologi Penelitian Kesehatan (Ed. Rev). Jakarta: Rineka Cipta.

Sitohang, I.B.S., Wasitaatmaja, S.M. 2016. IImu Penyakit Kulit dan Kelamin (7). Jakarta: FKUI.

Zari, S., Alrahmani, D. (2017). The Association Between Stress and Acne Among Female Medical Students in Jeddah, Saudi Arabia. Clinical, Cosmetic and Investigational Dermatology, 503506. 